\title{
Influence of MWCNTs and gamma irradiation on thermal characteristics of medical grade UHMWPE
}

\author{
P S RAMA SREEKANTH and S KANAGARAJ* \\ Department of Mechanical Engineering, Indian Institute of Technology Guwahati, Guwahati 781 039, India
}

MS received 12 April 2012; revised 21 April 2013

\begin{abstract}
Several techniques are available to characterize the influence of $\gamma$-irradiation on structural parameters of polymers; among which thermal characterization is more often used. The present work is aimed to study the influence of multi walled carbon nanotubes (MWCNTs) and $\gamma$-irradiation on polymer crystallinity, lamellar thickness, coefficient of thermal expansion (CTE) and thermal stability of UHMWPE. The chemically treated MWCNTs were homogenously dispersed in UHMWPE using a ball milling machine and compression moulded to make the nanocomposites with different concentration of MWCNTs. The nanocomposites were then $\gamma$-irradiated at a dose rate of $2.5 \mathrm{kGy} / \mathrm{h}$ up to $25,50,75,100 \mathrm{kGy}$ irradiation doses. The results obtained from TGA studies revealed that the presence of MWCNTs improved the thermal stability and onset temperature of degradation of nanocomposites. The CTE of nanocomposites was decreased with an increase of MWCNTs concentration and irradiation dose. The reduction of thermal expansion of nanocomposites aids in minimizing the dimensional fluctuation of them. It is concluded that irradiation and the presence of MWCNTs in UHMWPE not only improved the thermal stability of the composites but also enhanced their crystallinity and lamellar thickness.
\end{abstract}

Keywords. Nanocomposites; thermomechanical properties; differential scanning calorimetry; $\gamma$-irradiation.

\section{Introduction}

Ultra high molecular weight polyethylene (UHMWPE) has a unique role to play in total joint replacements owing to its distinct properties, where the crosslinking of polymer by $\gamma$ irradiation is being used as one of the techniques to improve its wear strength. Materials used in total joint replacements have higher friction coefficient. They usually warm up more than the natural joints during their long term application and higher loading activities viz. walking, cycling, etc. According to Pritchett (2011) and Bergmann et al (2001), the temperature of the hip implants (metal on polyethylene and ceramic on polyethylene) for a $60 \mathrm{~min}$ walk was reported to increase up to $45^{\circ} \mathrm{C}$, which was influenced by the weight of the patients and their activities etc. Lu and McKellop (1997) confirmed the increase of surface temperature of polyethylene up to $45^{\circ} \mathrm{C}$ using finite element analysis, where alumina was used as a femoral head. Other factors such as orthopedic operations and bone cement polymerization also influenced the heat generation, which led to the expansion of the implant materials (Stanczyk and Telega 2002), and thus it is expected to have a minor mechanical instability of the implants.

\footnotetext{
*Author for correspondence (kanagaraj@iitg.ernet.in)
}

The hip implant is a bearing couple separated by a thin film of synovial fluid lubrication. A small change in the dimension of the implant material due to its thermal expansion modifies the loading conditions and lubrication regimes, which influence the wear of the implant and consequently its longevity. If the synovial lubricant film thickness was less than the surface roughness of the implant, it resulted in asperity contact and wear of the implant (Vahid et al 2001). The radial clearance, which influences the bearing film thickness, had been usually around $250 \mu \mathrm{m}$ for a metalon-polyethylene hip prosthesis (Besong et al 2001). The change in radial clearance due to dimensional instability of the implant materials influenced the viscous behaviour of the bearing film leading to asperity contact of the bearing materials. Although UHMWPE maintained its properties at high temperatures for a short duration, it became more ductile at above $40{ }^{\circ} \mathrm{C}$ (Dostal 1987) and it is expected to have plastic flow of UHMWPE for a given geometry and loading condition leading to distortion of the bearing surfaces. The irradiation of polymeric implants led to increase of surface hardness and thus the sample was expected to have less surface deformation (Maadeed et al 2006). They also reported that the combined effect of one year shelf ageing of UHMWPE and irradiation at $400 \mathrm{kGy}$ showed the increase of $60 \%$ crystallinity compared to that of unaged samples. Oral et al (2005) blended $0,0 \cdot 1$ and 0.3 wt.\% of $\alpha$-tocopherol with UHMWPE and irradiated at $100 \mathrm{kGy}$. Though the level of crystallinity of all the test samples was increased as a result 
of irradiation and accelerated ageing, the sample containing 0 wt. $\% \alpha$-tocopherol exhibited higher crystallinity than either of the blend. Lee et al (2004) confirmed that the mechanical properties and melting point of $\gamma$-irradiated UHMWPE were improved by the radiation induced crosslinks. Stephens et al (2005) concluded that both crystallinity and lamellar thickness of UHMWPE were increased with higher dose and the rate of irradiation. Medel et al (2005) studied the microstructure of irradiated UHMWPE and reported that lamellar thickness and crystallinity of $25 \mathrm{kGy}$ irradiated UHMWPE were found to be increased by 18.5 and $9 \%$, respectively compared to that of unirradiated polymer. Maadeed et al (2010) investigated the microstructural changes of $\gamma$ irradiated UHMWPE and reported that the lamellar thickness of polymer was increased by $150 \%$ upon irradiation at $400 \mathrm{kGy}$. An increase of crystallinity by $26 \%$ was also reported at higher irradiation doses due to raise in degree of crosslinking and chain scission. Goldman et al (1998) found that the $\gamma$-irradiated UHMWPE aged for 10 months had a more ordered, lamellae structure than the unirradiated polymer suggesting an increase of crystallinity. Buchanan et al (2001) irradiated UHMWPE at 25 and $40 \mathrm{kGy}$ doses and reported that the density and crystallinity of polymer were increased due to irradiation. Morlanes et al (2011) reinforced UHMWPE with MWCNTs and irradiated at $90 \mathrm{kGy}$ and it was reported that irradiation of UHMWPE led to increase of its crystallinity, lamellar thickness and melting temperature.

Since the work is targeted towards total joint replacements, a few literatures on the biocompatibility of MWCNTs and nanocomposites is briefly discussed here. Firme and Bandaru (2010) reviewed on toxicity issues of MWCNTs and reported that functionalized MWCNTs are much less toxic due to more biocompatible functional groups attached on their surface. Guo et al (2007) and Wang et al (2004) have confirmed the biocompatibility of CNTs by injecting both intravenously and intraperitoneally into mice. Recent studies by Reis et al (2010) also confirmed the cytocompatibility of UHMWPE/MWCNTs wear debris with osteoblast like MG63 cells.

Even though a vast amount of literature reports the enhancement of structural parameters after irradiation of polyethylene, not many of them discuss the influence of concentration of MWCNTs and irradiation at different doses on thermal properties and dimensional stability of UHMWPE. The thermal expansion of UHMWPE due to frictional heating influences bearing clearance and consequently its wear. Thus, it must be given due consideration to enhance the longevity of the implant. In the present study, various parameters namely, (i) crystallinity, (ii) lamellar thickness, (iii) melting point, (iv) dimensional stability and (v) coefficient of thermal expansion of UHMWPE were evaluated for different concentrations of MWCNTs $(0.2,0.4,0.6$, $0.8,1.00,2.00 \mathrm{wt} . \%)$ and irradiation doses $(25,50,75$, $100 \mathrm{kGy}$ ) in order to understand the influencing parameters of UHMWPE/MWCNTs nanocomposites for implant applications.

\section{Materials and methods}

\subsection{Materials}

The MWCNTs were purchased from M/s Shenzhen Nanotech Port Co., Ltd., China. The specifications of as received MWCNTs are as follows: outer diameter 60-100 nm, length $5-15 \mu \mathrm{m}$, purity $>95 \%$ wt. $\%$, ash content $<1.5 \%$, density $2.16 \mathrm{~g} / \mathrm{cc}$, specific surface area $>200 \mathrm{~m}^{2} / \mathrm{g}$. UHMWPE grade GUR 1020 was received from M/s Ticona, Germany, and its specifications are as follows: molecular weight $4 \times 10^{6} \mathrm{~g} / \mathrm{mol}$, average particle size $140 \mu \mathrm{m}$, density of the processed sample $0.96 \mathrm{~g} / \mathrm{cc}$.

\subsection{UHMWPE/MWCNTs composites}

The MWCNTs were chemically treated as suggested by Esumi et al (1996) and it is briefly discussed here. The MWCNTs were suspended in the mixture of nitric and sulphuric acid by the volume ratio $1: 3$ and boiled at $140{ }^{\circ} \mathrm{C}$ for $40 \mathrm{~min}$. The mixture was cooled to room temperature and washed with deionized water till the supernatant attained a $\mathrm{pH}$ value around 7. The sample was dried in a hot air oven to remove the moisture content. The required quantity of chemically treated MWCNTs was mixed with UHMWPE powder at different weight fractions such as $0.2,0.4,0.6,0.8,1 \cdot 0$ and $2.0 \%$. The mixture was ball milled to ensure homogeneous dispersion of reinforcement in the polymer powder and then compression moulded to obtain the hemispherical cup of $28 \mathrm{~mm}$ inner diameter and $1 \mathrm{~mm}$ thickness. The compression pressure cycle has three main segments namely, compaction, sintering and repressing. During the compaction stage, the material was loaded (6.8 MPa) and unloaded (0 MPa) for five times, each for $90 \mathrm{~s}$ and the temperature was raised to $160{ }^{\circ} \mathrm{C}$ at the end of the compaction stage. The applied pressure was maintained at $3.8 \mathrm{MPa}$ for $5 \mathrm{~min}$ at $160{ }^{\circ} \mathrm{C}$ during the sintering stage and then it was once again increased to $6.8 \mathrm{MPa}$ for 5 min for repressing the molten polymer mixture. The sample was then cooled to room temperature by circulating water into the dies. The samples in the form of hemispherical cups representing acetabular cups were received from Prof. J A O Simoes, University of Aveiro, Portugal.

\subsection{Gamma irradiation}

The test specimens were $\gamma$-irradiated in air by ${ }^{60} \mathrm{Co}$ source at a dosage rate of $2.5 \mathrm{kGy} / \mathrm{h}$ for $25,50,75$ and $100 \mathrm{kGy}$ dosages at $\mathrm{M} / \mathrm{s}$ Microtrol Sterilization Private Limited, Bangalore, India, and the samples were characterized without any post irradiation treatments.

\subsection{Differential scanning calorimetry and thermogravimetric analysis (DSC and TGA)}

Calorimetric analysis of the test samples was performed using a Netzsch simultaneous thermal analyser, model STA 
$449 \mathrm{~F} 3$ from room temperature to $200{ }^{\circ} \mathrm{C}$ at a heating rate of $10 \mathrm{~K} / \mathrm{min}$. The sample holder, Alumina, was heated in a muffle furnace upto $1200{ }^{\circ} \mathrm{C}$ to remove any volatile contaminants present in the pan. Later, it was sonicated in ultrasonic bath and dried in an oven to ensure contaminant and moisture free sample holder. Alumina pan with perforated lid was used with a sample weighing 5-6 mg. Argon was used to purge the sample chamber and the furnace at 20 and $60 \mathrm{ml} / \mathrm{min}$, respectively. Gravimetric analysis was also performed on the same equipment to find the thermal stability of the test materials up to $600{ }^{\circ} \mathrm{C}$.

\subsection{Thermo mechanical analysis (TMA)}

The dimensional change of the test sample was measured using a thermo mechanical analyser, model SS 6000, Seiko Instruments Inc, Japan. A disk shaped specimen of $2 \mathrm{~mm}$ thickness and $8 \mathrm{~mm}$ diameter was used in this study. The LVDT expansion probe was preloaded by $100 \mathrm{mN}$ and in contact with the specimen to measure its dimensional change. The test temperature was varied from 32 to $85^{\circ} \mathrm{C}$ at a heating rate of $10 \mathrm{~K} / \mathrm{min}$. Both unirradiated and irradiated composite samples were tested and reported. In all cases, three samples were tested per material condition and the average of the results was reported.

\section{Results and discussion}

\subsection{Differential scanning calorimetry (DSC) studies}

In order to study the influence of $\gamma$-irradiation on various parameters like crystallinity, melting temperature and lamellar thickness, DSC studies were carried out on the samples.

Figures 1(a) and 1(b) show the DSC plots at 0 and $100 \mathrm{kGy}$ doses for different weight fraction of MWCNTs in UHMWPE in the temperature range of $80-160{ }^{\circ} \mathrm{C}$. It is observed from figure 1(a) that melting temperature of unirradiated nanocomposites was around $131.5^{\circ} \mathrm{C}$ (varied between 131.2 and $131.7{ }^{\circ} \mathrm{C}$ ), while at $100 \mathrm{kGy}$ irradiation dose, it was increased to $140.2{ }^{\circ} \mathrm{C}$ (varied between 140.0 and $140 \cdot 3{ }^{\circ} \mathrm{C}$ ), as shown in figure $1(\mathrm{~b})$. The increase of melting temperature of nanocomposites with irradiation dosage suggested that the melting process of the test samples was delayed due to the formation of crosslinks produced during the irradiation process (Premnath et al 1999). Furthermore, an increase of irradiation dose led to higher degree of crosslinking in the test material, and its melting process is expected to occur at higher temperature (Bhateja et al 1995).

It is noted from figures 1(a) and 1(b) that the presence of MWCNTs in polyethylene had no influence on the melting point of composites under both unirradiated and irradiated condition. The crystallinity of the nanocomposites, which significantly influences the mechanical properties, was obtained by normalizing the heat of fusion of nanocomposites with that of a $100 \%$ crystalline material, $289.4 \mathrm{~J} / \mathrm{g}$ in
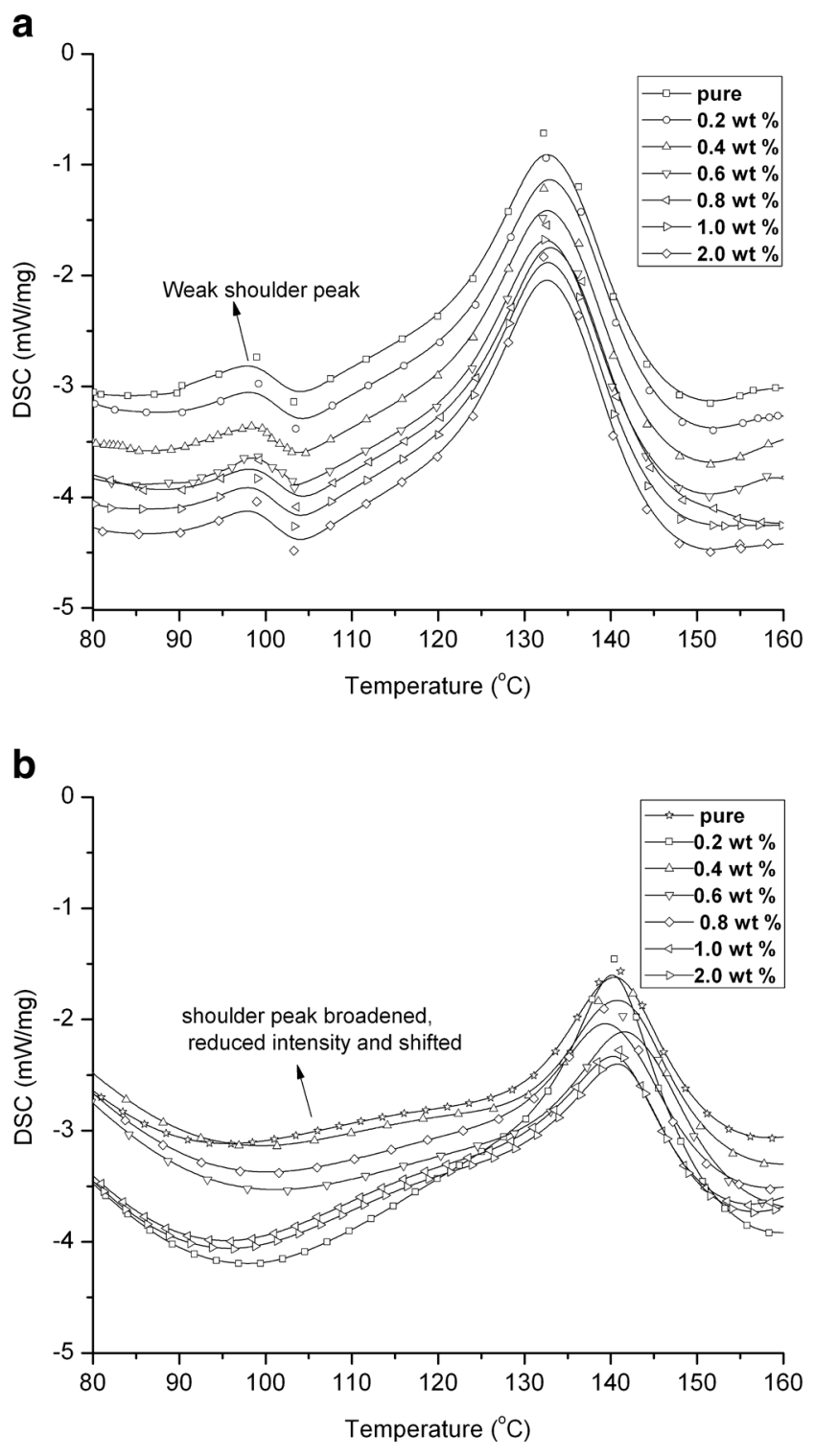

Figure 1. DSC plots of nanocomposites at (a) unirradiated and (b) $100 \mathrm{kGy} \gamma$-irradiated condition.

this case (ASTM F2625-10). A weak shoulder peak was observed in figure 1 (a) at around $100{ }^{\circ} \mathrm{C}$ prior to the melting endotherm of the unirradiated polymer composites. The presence of shoulder peak was an indication of the presence of small crystallites in the composites, which was also confirmed by Premnath et al (1999). It is observed from figure 1(b) that the broadened shoulder peak of nanocomposites at $100 \mathrm{kGy}$ dose was shifted to around $118{ }^{\circ} \mathrm{C}$ with reduced intensity. It is confirmed the formation of small crystallites in the amorphous region due to $\gamma$-irradiation generated radicals, where the broken chains were expected to form new lamellae in the amorphous region thus leading to increase of the crystallinity of polymer and its composites.

The influence of $\gamma$-irradiation and MWCNTs on crystallinity of the composites are shown figure 2(a). Figure 2(b) shows the effect of $\gamma$-irradiation on melting point of 

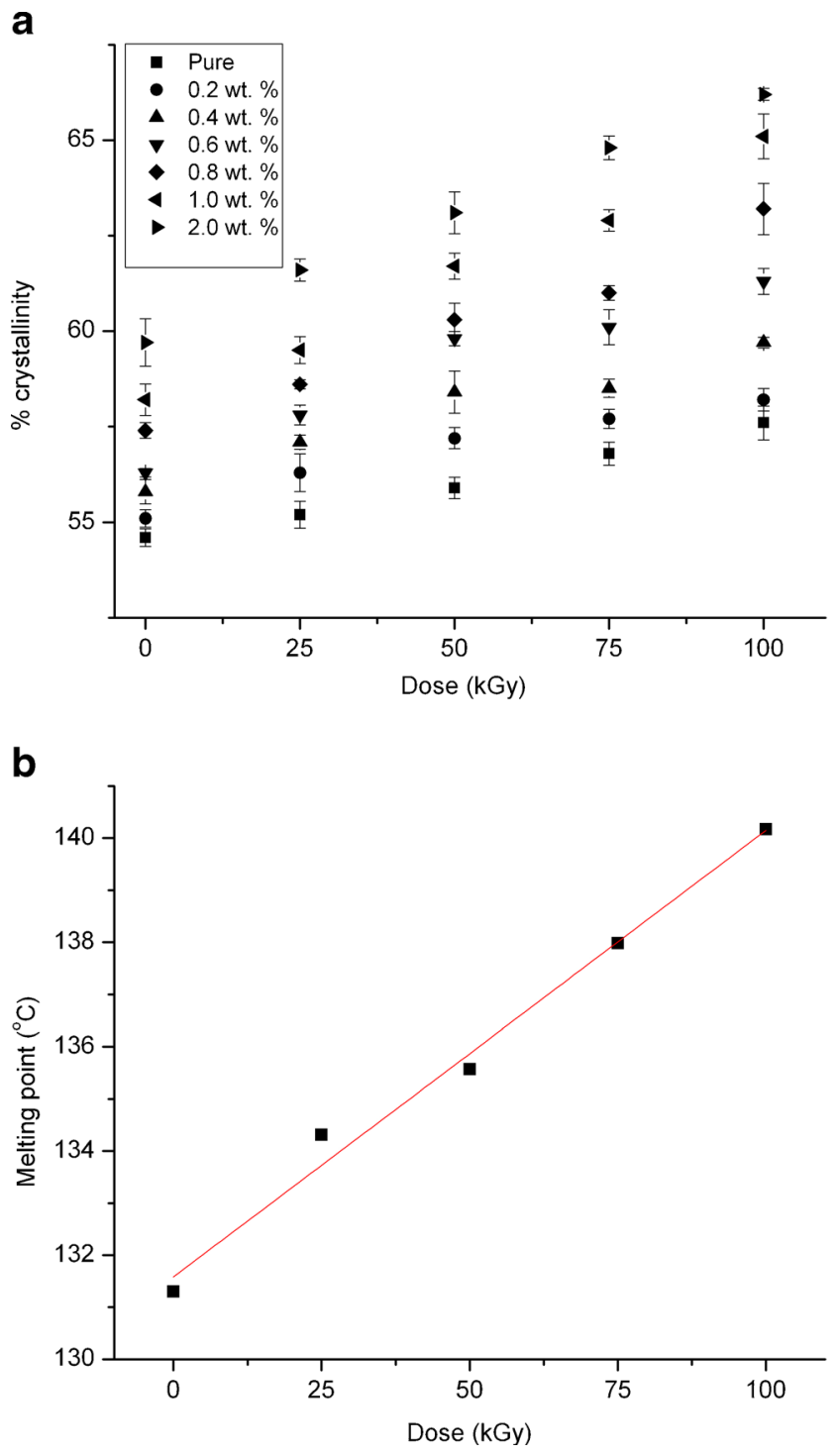

Figure 2. Influence of irradiation dose on (a) crystallinity and (b) melting point of nanocomposites.

the test material. It is observed from figure 2(a) that the crystallinity of UHMWPE was increased with both irradiation dosage and concentration of MWCNTs, which is also supported by published literature (Bhateja et al 1995; Kanagaraj et al 2007; Morlanes et al 2011). The enhancement of crystallinity of unirradiated composite with an increase of MWCNTs concentration was found to be $0,0 \cdot 9$, $2 \cdot 1,3 \cdot 1,5 \cdot 2,6 \cdot 5$ and $9 \cdot 3 \%$, whereas at $100 \mathrm{kGy}$ the corresponding enhancement was observed to be $5 \cdot 4,6 \cdot 5,9 \cdot 3$, $12 \cdot 2,15 \cdot 7,20 \cdot 5$ and $21 \cdot 2 \%$ for $0,0 \cdot 2,0 \cdot 4,0 \cdot 6,0 \cdot 8,1 \cdot 0$ and $2.0 \mathrm{wt} . \%$ MWCNTs in UHMWPE, respectively. An increase of crystallinity of the test sample with irradiation dose was due to the fact that the chain scission occurred in addition to the crosslinking during the irradiation process and these two processes progressed to a higher degree with an increase of dosage level (Maadeed et al 2010). It was reported by Bhateja et al (1995) that the broken chains formed by the chain scission process were rearranged into the existing crystals, thus an increase of the crystal perfection in an irradiated UHMWPE occurred. According to Kanagaraj et al (2007), MWCNTs acted as sites for nucleation of crystallization of polymer and thus it enhanced the crystallinity of the composite. It was observed from figure 2(b) that the melting point of pure polymer was linearly increased with irradiation dose. It is due to the fact that the crosslinks formed between the molecular chains as a result of irradiation process need to be broken before the material is melted and thus it demands higher heat input leading to an increase of melting temperature compared to that of unirradiated polymer. As the melt temperature of UHMWPE was not changed significantly by the presence of MWCNTs, the influence of irradiation dose on melting temperature of UHMWPE was shown in figure 2(b).

UHMWPE softens above $40^{\circ} \mathrm{C}$, which is nearly $1 / 3$ of its melting temperature (Besong et al 2001). By applying the same proportion, a shift in softening temperature of irradiated UHMWPE by $3-4{ }^{\circ} \mathrm{C}$ was expected due to increase of its melting temperature by $9{ }^{\circ} \mathrm{C}$, which helps to reduce the risk of plastic flow of polymer up to $45^{\circ} \mathrm{C}$.

The melting temperature of irradiated polymer is a combined effect of the increased lamellar thickness and the irradiation induced crosslinks between the molecular chains. In case of unirradiated polymer, the melting temperature depends on only lamellar thickness, which is calculated using Thomson's equation, and it is a function of melting temperature of the test material (Stephens et al 2005). The lamellar thickness $(l)$ of unirradiated and irradiated test sample (pure polymer and $2 \mathrm{wt} . \%$ nanocomposite at $0 \mathrm{kGy}$ and $100 \mathrm{kGy}$ dose) was calculated using both Thomson's equation (1) and Debye-Scherrer equation (2) (Perepechko 1981)

$$
\begin{aligned}
& l=\frac{2 \sigma_{\mathrm{e}} 10^{3}}{\Delta H_{\mathrm{m}} \rho_{\mathrm{c}}\left(1-\frac{T_{\mathrm{m}}}{T_{\mathrm{m}}^{\mathrm{o}}}\right)} \mathrm{nm}, \\
& l=\frac{K \lambda}{B \cos \theta} \mathrm{nm}
\end{aligned}
$$

where $T_{\mathrm{m}}^{\mathrm{o}}$ is the melting temperature of $100 \%$ crystalline polyethylene, $418.7 \mathrm{~K}, \Delta H_{\mathrm{m}}$, the heat of fusion of $100 \%$ crystalline polyethylene, $289.4 \mathrm{~kJ} / \mathrm{kg}, \sigma_{\mathrm{e}}$, the surface free energy, $90 \mathrm{~mJ} / \mathrm{m}^{2}$ and $\rho_{\mathrm{c}}$, the density, $967 \mathrm{~kg} / \mathrm{m}^{3}, T_{\mathrm{m}}$, the melting temperature of the test sample in $\mathrm{K}$ and $B$ the full width at half maximum of the XRD peak and $K=0 \cdot 9$. From the DSC results, the melting temperature of unirradiated and $100 \mathrm{kGy}$ irradiated pure polymer was found to be 131.2 and $140 \cdot 2{ }^{\circ} \mathrm{C}$, respectively. According to Thomson's equation, the lamellar thickness of pure polymer was found to increase from 18.57 to $48.96 \mathrm{~nm}$ upon irradiation at $100 \mathrm{kGy}$, which corresponds to an increase of approximately $164 \%$.

Figure 3 shows the XRD pattern of pure polymer and 2 wt. $\%$ nanocomposite at unirradiated and irradiated condition. Based on the Debye equation, the lamellar thickness of pure polymer was found to be increased from 
$21.39 \mathrm{~nm}$ for unirradiated polymer to $23.4 \mathrm{~nm}$ for $100 \mathrm{kGy}$ irradiated polymer, which corresponds to approximately $10 \%$ enhancement. Similarly, the lamellar thickness of 2 wt.\% nanocomposite was increased from 22.1 to $26.7 \mathrm{~nm}$, i.e. $20.8 \%$ enhancement, whereas the data obtained from the Thomson's equation showed $164 \%$ enhancement. It is to be noted that the difference in lamellar thickness of unirradiated sample calculated using Thomson's equation and Debye equation was within $15 \%$, whereas the same for $100 \mathrm{kGy}$ irradiated sample was observed to be $109 \%$. As the crosslink generated during the irradiation process is not considered in Thomson's equation, the lamellar thickness calculated using the same led to misinterpretation of the data. Thus, it is recommended to use Debye equation for irradiated sample.

\subsection{Thermogravimetric analysis}

Figures 4(a) and 4(b) show the TGA results of nanocomposites at unirradiated and $100 \mathrm{kGy}$ irradiation condition, respectively. It is observed that the thermal stability of UHMWPE was significantly improved by the irradiation dose and the reinforcement of MWCNTs.

The onset temperature of degradation of pure UHMWPE at unirradiated and $100 \mathrm{kGy}$ irradiated condition was found to be 393 and $416{ }^{\circ} \mathrm{C}$, respectively. While the same for 2 wt.\% nanocomposite was observed to be 446 and $462{ }^{\circ} \mathrm{C}$ at 0 and $100 \mathrm{kGy}$ irradiation dose, respectively. A similar trend was also observed at other irradiation doses. The results obtained from the TGA measurements revealed that the temperature at which the maximum rate of decomposition occurs was increased with MWCNTs concentration due to their thermal properties and high thermal stability. The heat required for a given temperature raise in polymer is 2.6 times more than that of the same required for MWCNTs (Sreekanth and Kanagaraj 2013). When equal amount of heat is supplied to MWCNTs and UHMWPE, the raise in

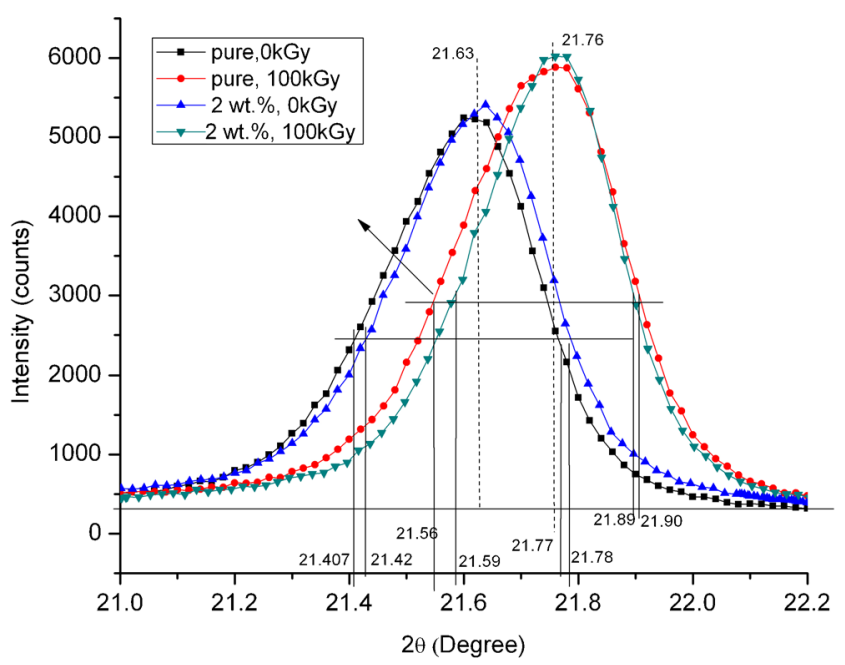

Figure 3. XRD Spectra of pure and 2 wt. $\%$ nanocomposite at $0 \mathrm{kGy}$ and $100 \mathrm{kGy}$ irradiation doses. temperature is higher for MWCNTs than the polymer. As the thermal conductivity of MWCNTs is few order higher than that of the polymer and the maximum heat flow is possible through the path of least resistance, a greater amount of heat is expected to flow through MWCNTs than the polymer. Thus, the onset temperature of degradation of UHMWPE occurred at higher temperature with an increase of the concentration of MWCNTs. Furthermore, the crosslinks produced during the irradiation process made polyethylene more thermally stable at high temperature.

\subsection{Thermomechanical analysis and dimensional stability}

Thermal expansion of virgin unirradiated UHMWPE measured at different temperature ranges is shown in figure 5 . The average coefficient of thermal expansion (CTE) of polymer at any temperature range was calculated with reference to $32^{\circ} \mathrm{C}$ and the values are inscribed in figure 5 . It is observed
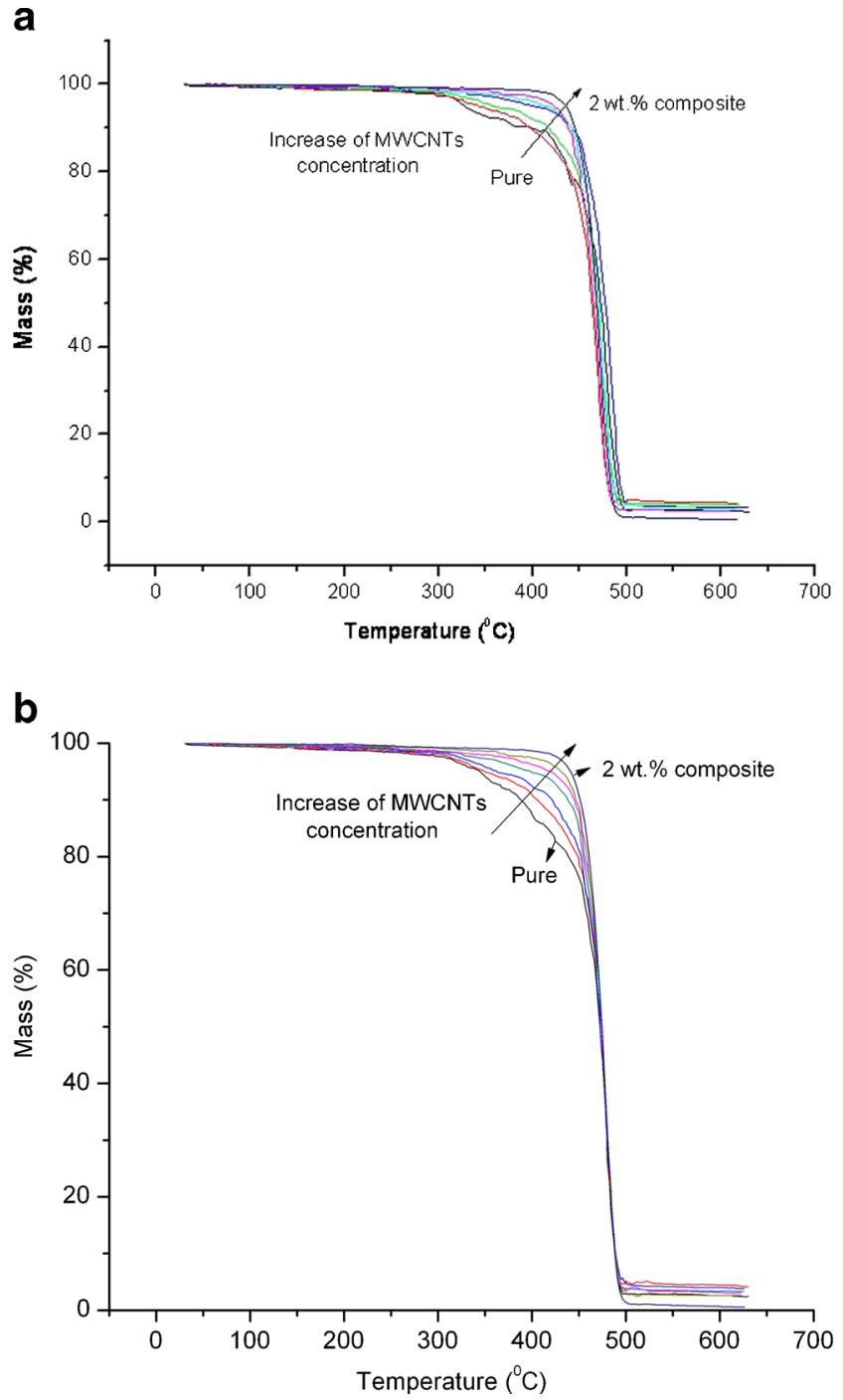

Figure 4. TGA plots of UHMWPE/MWCNTs nanocomposites at (a) $0 \mathrm{kGy}$ and (b) $100 \mathrm{kGy}$ irradiation doses. 


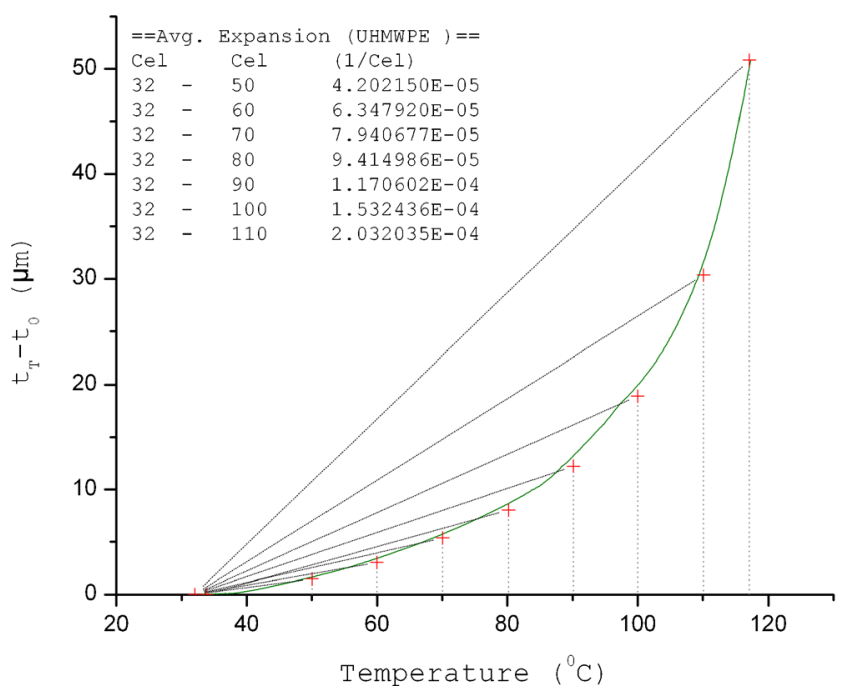

Figure 5. Thermal expansion of pure UHMWPE in the temperature range of $32-120^{\circ} \mathrm{C}$. that the average CTE was found to be $4.20 \times 10^{-5} \mathrm{~m} / \mathrm{m}-$ $\mathrm{K}$ at $50{ }^{\circ} \mathrm{C}$, which was increased to $9.41 \times 10^{-5} \mathrm{~m} / \mathrm{m}-\mathrm{K}$ at $80{ }^{\circ} \mathrm{C}$. The relation between CTE of polymer and temperature was found to be linear till $85^{\circ} \mathrm{C}$ beyond which it has progressed exponentially. The average CTE of pure UHMWPE was found to be $1.17 \times 10^{-4}$ and $2.03 \times 10^{-4} \mathrm{~m} / \mathrm{m}-\mathrm{K}$ in the temperature range of $32-90^{\circ} \mathrm{C}$ and $32-110^{\circ} \mathrm{C}$, respectively. This is consistent with the manufacturer's data sheet, where the values are in the range of $1-2 \times 10^{-4} \mathrm{~m} / \mathrm{m}-\mathrm{K}$. Since the present study is focused only upto $80^{\circ} \mathrm{C}$, the reported CTE values are in the order of $10^{-5} \mathrm{~m} / \mathrm{m}-\mathrm{K}$.

The dimensional stability of nanocomposites at 0 and $100 \mathrm{kGy}$ irradiation dosage in the temperature range of 32$45{ }^{\circ} \mathrm{C}$ and $32-85{ }^{\circ} \mathrm{C}$ is shown in figures $6(\mathrm{a})-6(\mathrm{~d})$. The temperature range was selected by considering the fact that the surface temperature of polyethylene was raised up to $45{ }^{\circ} \mathrm{C}$ in case of metal or ceramic prosthesis (Bergmann et al 2001; Pritchett 2011), and the implant temperature was increased up to $80^{\circ} \mathrm{C}$ (Stanczyk and Telega 2002), during
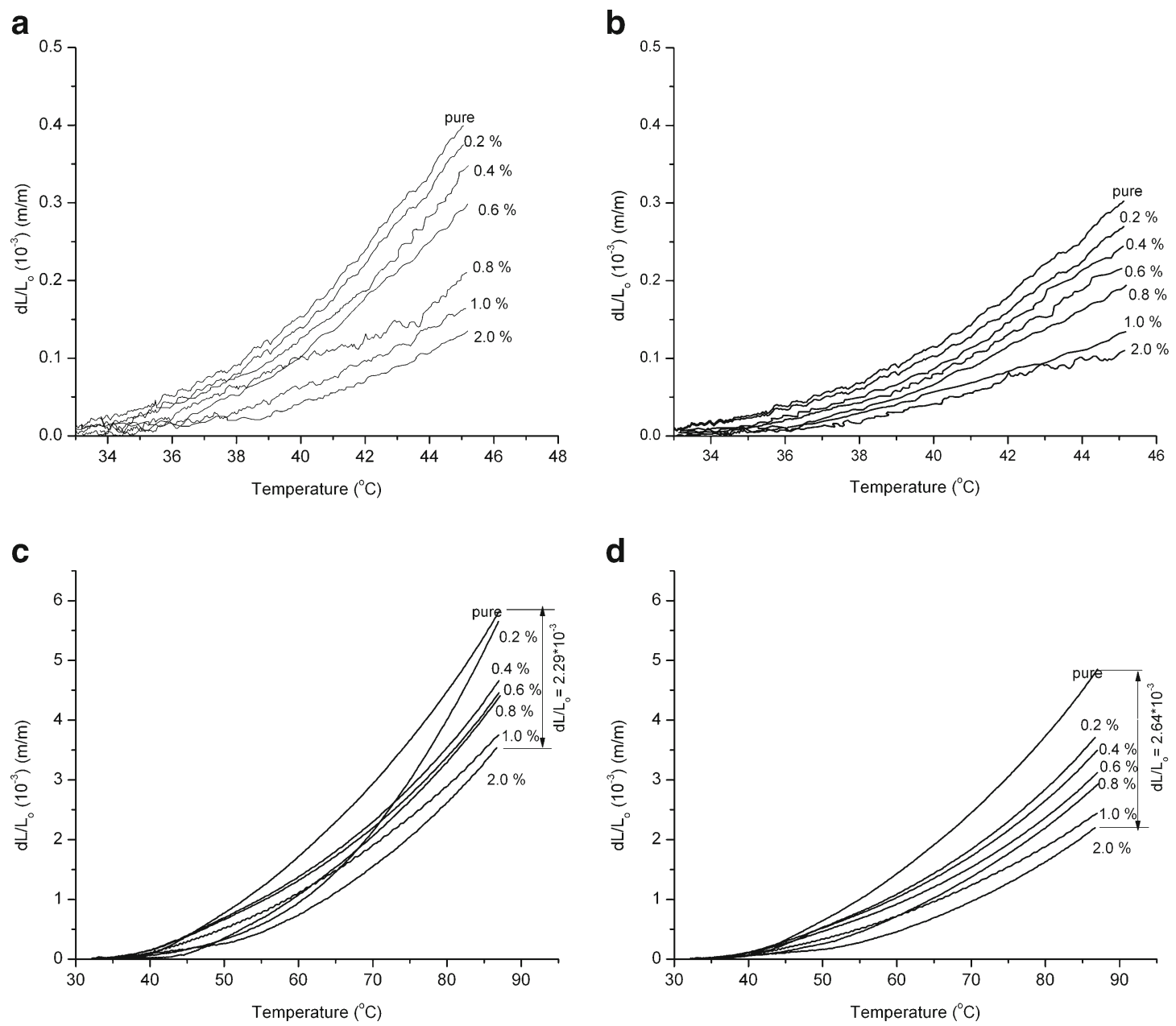

Figure 6. Change of length vs temperature (a) $0 \mathrm{kGy}$ composites $32-45{ }^{\circ} \mathrm{C}$, (b) $100 \mathrm{kGy}$ composites $32-45^{\circ} \mathrm{C}$, (c) $0 \mathrm{kGy}$ composites $32-85^{\circ} \mathrm{C}$ and (d) $100 \mathrm{kGy}$ irradiated $32-85^{\circ} \mathrm{C}$. 
Table 1(a). Coefficient of thermal expansion of unirradiated test samples upto $45^{\circ} \mathrm{C}$.

\begin{tabular}{|c|c|c|c|c|c|c|c|}
\hline \multirow{3}{*}{$\begin{array}{l}\text { Temperature } \\
\left({ }^{\circ} \mathrm{C}\right)\end{array}$} & \multicolumn{7}{|c|}{ Coefficient of thermal expansion CTE $\left(10^{-6}\right)(\mathrm{m} / \mathrm{m}-\mathrm{K})$} \\
\hline & \multirow{2}{*}{$\begin{array}{c}\text { Pure } \\
\text { UHMWPE }\end{array}$} & \multicolumn{6}{|c|}{ Concentration of MWCNTs (wt.\%) } \\
\hline & & $0.2 \%$ & $0.4 \%$ & $0.6 \%$ & $0.8 \%$ & $1.0 \%$ & $2.0 \%$ \\
\hline 38 & $15 \cdot 11$ & $14 \cdot 44$ & $12 \cdot 68$ & $10 \cdot 73$ & $9 \cdot 66$ & $4 \cdot 76$ & $3 \cdot 875$ \\
\hline 39 & $17 \cdot 2$ & $16 \cdot 44$ & $13 \cdot 65$ & $12 \cdot 13$ & $10 \cdot 8$ & $5 \cdot 822$ & $3 \cdot 58$ \\
\hline 40 & $19 \cdot 13$ & $18 \cdot 29$ & $15 \cdot 82$ & $13 \cdot 5$ & $11 \cdot 2$ & $7 \cdot 69$ & $5 \cdot 52$ \\
\hline 41 & $21 \cdot 65$ & $20 \cdot 7$ & $17 \cdot 26$ & $15 \cdot 09$ & 12.69 & 9.53 & $7 \cdot 17$ \\
\hline 42 & 23.92 & $22 \cdot 87$ & $18 \cdot 66$ & $17 \cdot 3$ & $13 \cdot 16$ & 11.56 & $10 \cdot 08$ \\
\hline 43 & $26 \cdot 82$ & $25 \cdot 64$ & $20 \cdot 97$ & 19.71 & $15 \cdot 4$ & $13 \cdot 61$ & $11 \cdot 21$ \\
\hline 44 & 28.03 & $26 \cdot 8$ & $23 \cdot 86$ & $21 \cdot 8$ & $16 \cdot 9$ & $15 \cdot 59$ & 12.92 \\
\hline 45 & $30 \cdot 62$ & $29 \cdot 27$ & $26 \cdot 3$ & $23 \cdot 19$ & 18.88 & $17 \cdot 44$ & $15 \cdot 14$ \\
\hline
\end{tabular}

Table 1(b). Coefficient of thermal expansion of unirradiated test samples from 50 to $80{ }^{\circ} \mathrm{C}$.

\begin{tabular}{|c|c|c|c|c|c|c|c|}
\hline \multirow{3}{*}{$\begin{array}{l}\text { Temperature } \\
\left({ }^{\circ} \mathrm{C}\right)\end{array}$} & \multicolumn{7}{|c|}{ Coefficient of thermal expansion CTE $\left(10^{-6}\right)(\mathrm{m} / \mathrm{m}-\mathrm{K})$} \\
\hline & \multirow{2}{*}{$\begin{array}{c}\text { Pure } \\
\text { UHMWPE }\end{array}$} & \multicolumn{6}{|c|}{ Concentration of MWCNTs (wt.\%) } \\
\hline & & $0.2 \%$ & $0.4 \%$ & $0.6 \%$ & $0.8 \%$ & $1.0 \%$ & $2.0 \%$ \\
\hline 50 & $43 \cdot 02$ & $40 \cdot 9$ & $38 \cdot 5$ & $36 \cdot 8$ & 31.96 & $29 \cdot 0$ & 14.63 \\
\hline 60 & 61.45 & $53 \cdot 9$ & $49 \cdot 5$ & $47 \cdot 3$ & $39 \cdot 5$ & $38 \cdot 6$ & $26 \cdot 1$ \\
\hline 70 & $77 \cdot 49$ & $66 \cdot 4$ & $60 \cdot 6$ & $57 \cdot 9$ & $54 \cdot 2$ & $50 \cdot 2$ & $40 \cdot 7$ \\
\hline 80 & 93.61 & $86 \cdot 3$ & $73 \cdot 8$ & $70 \cdot 6$ & $68 \cdot 6$ & $60 \cdot 3$ & $54 \cdot 7$ \\
\hline
\end{tabular}

Table 1(c). Coefficient of thermal expansion of $100 \mathrm{kGy}$ irradiated test samples upto $45^{\circ} \mathrm{C}$.

\begin{tabular}{|c|c|c|c|c|c|c|c|}
\hline \multirow{3}{*}{$\begin{array}{l}\text { Temperature } \\
\left({ }^{\circ} \mathrm{C}\right)\end{array}$} & \multicolumn{7}{|c|}{ Coefficient of thermal expansion CTE $\left(10^{-6}\right)(\mathrm{m} / \mathrm{m}-\mathrm{K})$} \\
\hline & \multirow[b]{2}{*}{ Pure } & \multicolumn{6}{|c|}{ Concentration of MWCNTs (wt.\%) } \\
\hline & & $0 \cdot 2 \%$ & $0.4 \%$ & $0.6 \%$ & $0.8 \%$ & $1.0 \%$ & $2.0 \%$ \\
\hline 38 & $11 \cdot 33$ & $10 \cdot 11$ & $8 \cdot 45$ & $7 \cdot 2$ & $6 \cdot 24$ & 4.975 & $2 \cdot 74$ \\
\hline 39 & $12 \cdot 9$ & $11 \cdot 51$ & $9 \cdot 921$ & $8 \cdot 304$ & $7 \cdot 885$ & $6 \cdot 232$ & $4 \cdot 39$ \\
\hline 40 & $14 \cdot 76$ & $12 \cdot 8$ & $10 \cdot 93$ & $10 \cdot 09$ & $8 \cdot 78$ & $7 \cdot 17$ & $5 \cdot 18$ \\
\hline 41 & 14.93 & 14.46 & $12 \cdot 9$ & 11.41 & $9 \cdot 81$ & $7 \cdot 64$ & $6 \cdot 18$ \\
\hline 42 & 17.94 & $16 \cdot 014$ & $14 \cdot 62$ & 13.07 & $11 \cdot 24$ & 8.49 & $7 \cdot 18$ \\
\hline 43 & $20 \cdot 11$ & $17 \cdot 95$ & $16 \cdot 52$ & $13 \cdot 88$ & $12 \cdot 81$ & $9 \cdot 61$ & $8 \cdot 33$ \\
\hline 44 & 21.02 & $18 \cdot 76$ & $17 \cdot 92$ & $15 \cdot 7$ & $14 \cdot 17$ & $11 \cdot 31$ & 8.56 \\
\hline 45 & 22.96 & $20 \cdot 49$ & $18 \cdot 78$ & $16 \cdot 59$ & $15 \cdot 07$ & $13 \cdot 34$ & $10 \cdot 08$ \\
\hline
\end{tabular}

Table 1(d). Coefficient of thermal expansion of $100 \mathrm{kGy}$ irradiated test samples from 50 to $80^{\circ} \mathrm{C}$.

\begin{tabular}{|c|c|c|c|c|c|c|c|}
\hline \multirow{3}{*}{$\begin{array}{l}\text { Temperature } \\
\left({ }^{\circ} \mathrm{C}\right)\end{array}$} & \multicolumn{7}{|c|}{ Coefficient of thermal expansion CTE $\left(10^{-6}\right)(\mathrm{m} / \mathrm{m}-\mathrm{K})$} \\
\hline & \multirow[b]{2}{*}{ Pure } & \multicolumn{6}{|c|}{ Concentration of MWCNTs (wt.\%) } \\
\hline & & $0 \cdot 2 \%$ & $0 \cdot 4 \%$ & $0.6 \%$ & $0 \cdot 8 \%$ & $1.0 \%$ & $2.0 \%$ \\
\hline 50 & $35 \cdot 85$ & $29 \cdot 64$ & $28 \cdot 88$ & $25 \cdot 7$ & $18 \cdot 9$ & $14 \cdot 23$ & $9 \cdot 1$ \\
\hline 60 & $51 \cdot 21$ & $38 \cdot 9$ & $37 \cdot 14$ & $33 \cdot 1$ & $26 \cdot 23$ & $25 \cdot 69$ & $16 \cdot 27$ \\
\hline 70 & $64 \cdot 57$ & $48 \cdot 3$ & $45 \cdot 46$ & $40 \cdot 56$ & $36 \cdot 14$ & $32 \cdot 68$ & $25 \cdot 45$ \\
\hline 80 & $78 \cdot 01$ & $59 \cdot 924$ & $55 \cdot 41$ & 49.45 & $45 \cdot 76$ & $39 \cdot 24$ & 34.02 \\
\hline
\end{tabular}


the bone cement polymerization and other basic orthopedic operations. The CTE of unirradiated pure polymer upto 45 and $50-80{ }^{\circ} \mathrm{C}$ is shown in table 1 (a) and $1(\mathrm{~b})$, respectively and the same for $100 \mathrm{kGy}$ irradiated samples is shown in table $1(\mathrm{c})$ and $1(\mathrm{~d})$.

It is noted from figures 6(a) and 6(b) that the thermal expansion of all the test materials was increased with temperature. However, the rate of increase of thermal expansion was reduced with an increase of concentration of MWCNTs. The maximum value of thermal expansion was observed for pure UHMWPE and minimum one was observed for $2 \mathrm{wt} \%$ nanocomposite, which confirmed the improvement of dimensional stability of UHMWPE by reinforcing MWCNTs. It is observed from figure 6(a) that the linear strain of $2 \mathrm{wt} \%$ nanocomposite at $45{ }^{\circ} \mathrm{C}$ was decreased by $60 \%$ compared to that of virgin polymer, while the corresponding reduction was $65 \%$ for the same test sample irradiated at $100 \mathrm{kGy}$ dose, as shown in figure 6(b). The linear strain of pure polymer irradiated at $100 \mathrm{kGy}$ was reduced by $24 \%$ compared to that of unirradiated sample and the corresponding reduction for 2 wt. $\%$ nanocomposites was found to be $25.5 \%$. The results

a

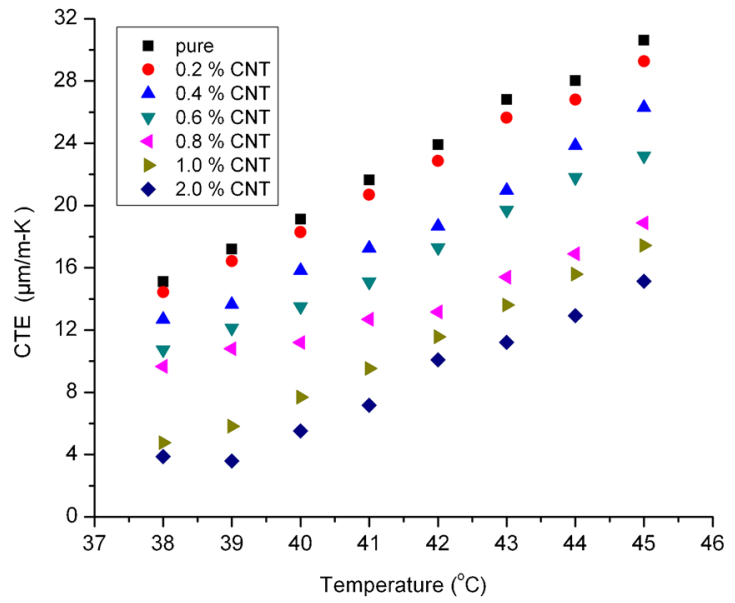

C

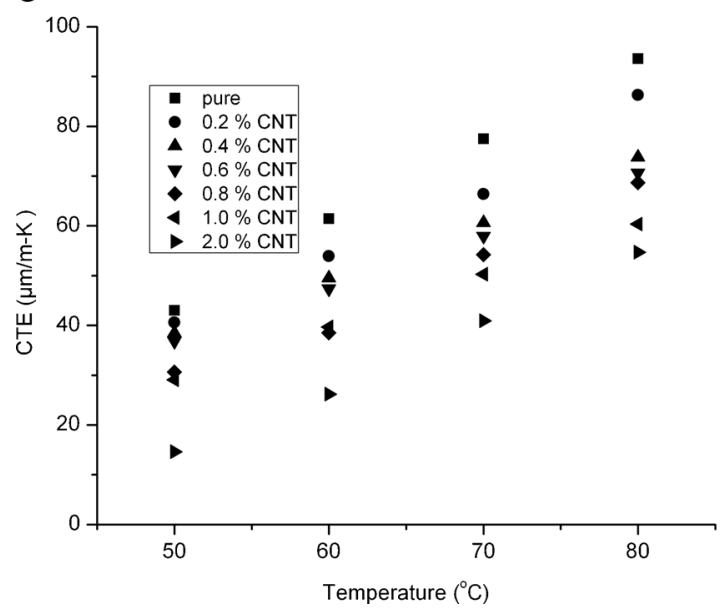

indicated that the linear strain of pure polymer was reduced by $72 \%$ upon irradiation at $100 \mathrm{kGy}$ dose and an addition of 2 wt.\% MWCNTs. It is due to the fact that the crosslinking induced by the irradiation resulted in long molecular chains with infinite mass restricting the mobility of polymer chains and led to the reduction of linear thermal expansion of polymer and nanocomposites (Premnath et al 1999). It is noticed from figures 6(c) and 6(d) that the difference between linear strain of pure polymer and 2 wt. $\%$ composite at 0 and $100 \mathrm{kGy}$ was $2.29 \times 10^{-3}$ and $2.64 \times 10^{-3} \mathrm{~m} / \mathrm{m}$, respectively, at $85{ }^{\circ} \mathrm{C}$. The linear strain of $2 \mathrm{wt} . \%$ nanocomposite under unirradiated and irradiated state was found to be 15 and $20 \%$, respectively, less than that of pure UHMWPE.

The CTE of both unirradiated and irradiated nanocomposites was calculated in the temperature range of $38-45^{\circ} \mathrm{C}$ and 50-80 ${ }^{\circ} \mathrm{C}$, where the reference temperature was considered as $32{ }^{\circ} \mathrm{C}$. The $\mathrm{CTE}$ of test sample was calculated using the following equation:

$$
\alpha=\left(\frac{\Delta t}{\Delta T}\right) \times \frac{t}{l}
$$

b

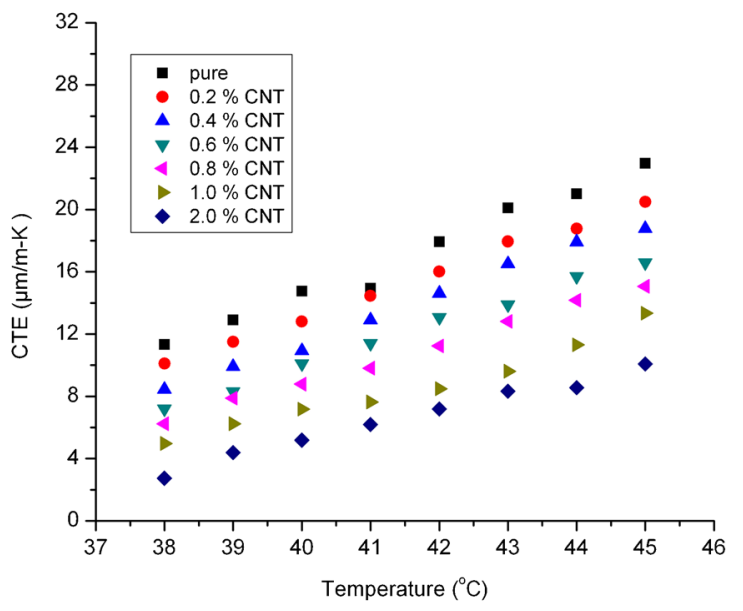

d

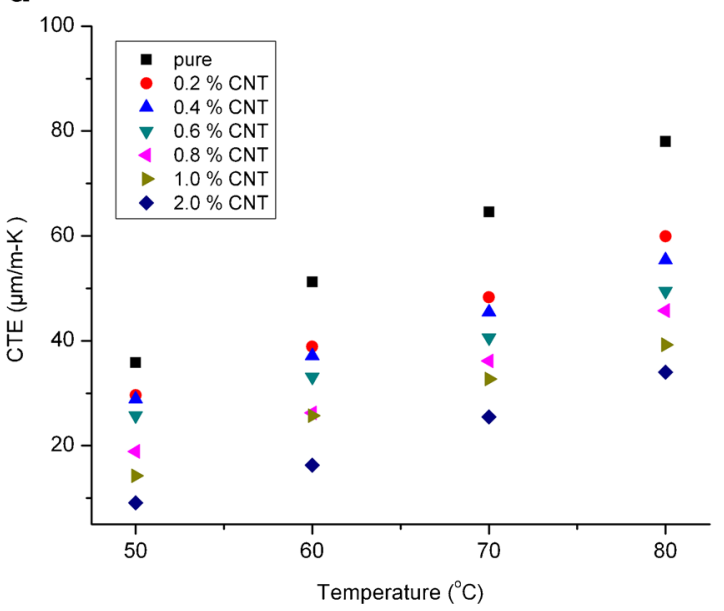

Figure 7. Thermal expansion vs temperature of (a) $0 \mathrm{kGy}$ composites $38-45^{\circ} \mathrm{C}$, (b) $100 \mathrm{kGy}$ composites $38-45^{\circ} \mathrm{C}$, (c) $0 \mathrm{kGy}$ composites $50-80{ }^{\circ} \mathrm{C}$ and (d) $100 \mathrm{kGy}$ irradiated $50-80{ }^{\circ} \mathrm{C}$. 
where $\Delta t$ is the change in length for a $\Delta T$ temperature difference and $t$, the initial thickness of the sample.

Figures 7(a)-7(d) show the variation of CTE of nanocomposites at 0 and $100 \mathrm{kGy}$ in the above referred temperature ranges. It is observed that the CTE of pure polymer and nanocomposites was increased with temperature. However, it has been greatly restricted by the addition of MWCNTs. The CTE of unirradiated polymer at 38 and $45^{\circ} \mathrm{C}$ was calculated to be $15 \cdot 1$ and $30.6 \mu \mathrm{m} / \mathrm{m}-\mathrm{K}$, respectively. However, it was reduced by 77 and $51 \%$ for $2 \mathrm{wt} \%$ nanocomposites for the same temperature range. Similarly, the CTE of $100 \mathrm{kGy}$ irradiated pure polymer at 38 and $45{ }^{\circ} \mathrm{C}$ was noted to be 11.3 and $22.9 \mu \mathrm{m} / \mathrm{m}-\mathrm{K}$, respectively and it was reduced by 76 and $56 \%$ for $2 \mathrm{wt} . \%$ nanocomposite. It is inferred from the above data that CTE of pure polymer at $45{ }^{\circ} \mathrm{C}$ was reduced by $51 \%$ and $83.7 \%$ upon addition of 2 wt. $\%$ MWCNTs and $100 \mathrm{kGy}$ irradiated 2 wt.\% nanocomposites, respectively. The dimensional stability of pure polymer at $0 \mathrm{kGy}$ was improved by the addition of 2 wt.\% MWCNTs and a further enhancement was noticed when it was irradiated at $100 \mathrm{kGy}$. As the dimensional stability of bearing materials helps to maintain the lubricating film thickness, it leads to an inference that the heat generation against articulating surfaces will be minimized by adding MWCNTs and $\gamma$-irradiation in virgin UHMWPE. Figures 7(c) and 7(d) show CTE of nanocomposites in the temperature range of $50-80{ }^{\circ} \mathrm{C}$, where the reference temperature was $32{ }^{\circ} \mathrm{C}$. The CTE of pure polymer at $80{ }^{\circ} \mathrm{C}$ was reduced by $41 \%$ by reinforcing 2 wt. $\%$ MWCNTs under unirradiated condition and it was decreased by $56.3 \%$ at $100 \mathrm{kGy}$. Similarly, the CTE of pure polymer was reduced by $17 \%$ upon irradiation at $100 \mathrm{kGy}$, whereas the cumulative effect of irradiation and $2 \mathrm{wt} . \%$ MWCNTs reinforcement led to the reduction of CTE by $64 \%$. The reduction of CTE of MWCNTs reinforced UHMWPE could be attributed to very low intrinsic thermal expansion of nanotubes, which is $26 \mathrm{~nm}$ up to $800 \mathrm{~K}$ (Kwon et al 2004), and thus it is expected to restrict the CTE of pure polymer. Moreover, MWCNTs have very high specific surface area and hence the interfacial area between MWCNTs and polymer matrix is of very high order resulting in the reduction of CTE of the composites. Reduction of CTE of UHMWPE by irradiation and reinforcement of MWCNTs is expected to minimize the fluctuation of dimension of the bearing couple. It aids in minimizing the asperity contact leading to the reduction of heat generation between the articulating surfaces.

\section{Conclusions}

- The crystallinity and thermal stability of UHMWPE were significantly enhanced by the addition of MWCNTs and $\gamma$-irradiation.

- Melting temperature of UHMWPE was not influenced by the reinforcement of MWCNTs but depends on the irradiation dosage level.
- Significant enhancement of lamellar thickness of UHMWPE was observed by the irradiation process but not by the reinforcement of MWCNTs.

- Dimensional stability of the composite was greatly improved by the presence of MWCNTs and $\gamma$-irradiation further enhances it.

- Both Debye-Scherrer equation and Thompson equation can be used to calculate the lamellar thickness of unirradiated composites within experimental deviation.

- Only Debye-Scherrer equation is recommended to calculate lamellar thickness of the irradiated sample.

\section{Acknowledgements}

Authors acknowledge the assistance received from Mr. N Naresh Kumar, IITG; Prof. J A O Simoes, University of Aveiro, Portugal; M/s Microtrol Sterilization Private Limited, Bangalore; and Central Instruments Facility and Materials science laboratory of IITG. Authors also acknowledge the funding support received from DST through a project IDP/Med/04/2009.

\section{References}

ASTM F2625-10. Standard Test Method for Measurement of Enthalpy of Fusion, Percent Crystallinity, and Melting Point of Ultra-High-Molecular Weight Polyethylene by Means of Differential Scanning Calorimetry [reapproved 2010]

Bergmann G, Graichen F, Rohlmann A, Verdonschot N and van Lenthe G H 2001 J. Biomech. 34421

Besong A, Jin Z M and Fisher J 2001 47th annual meeting (San Francisco, California: Orthopaedic Research Society)

Bhateja S K, Duerst R W, Martens J A and Andrews E H 1995 J. Macromol. Sci. R. M. C35 581

Buchanan F J, White J R, Sim B and Downes S 2001 J. Mater. Sci.Mater. M. 12297

Dostal C A 1987 Engineering materials handbook (USA: ASM International) Vol. 2

Engineering materials handbook 1987 Vol 2, ASM International

Esumi K, Ishigami M, Nakajima A, Sawada K and Honda H 1996 Carbon 34279

Firme III C P and Bandaru P R 2010 Nanomed. Nanotech. Biol. Med. 6245

Goldman M, Gronsky R and Pruitt L 1998 J. Mater. Sci.-Mater. M. 9207

Guo J, Zhang X, Li Q and Li W 2007 Nucl. Med. Biol. 34579

Kanagaraj S, Varanda F R, Zhiltsova T V, Oliveira M S A and Simoes J A O 2007 Compos. Sci. Technol. 673071

Kwon Y K, Berber S and Tománek D 2004 Phys. Rev. Lett. 92 015901-1

Lee C S, Yoo S H and Jho J Y 2004 Macromol. Res. 12112

Lu Z and McKellop H 1997 J. Engg. Med. 211101

Maadeed M A A, Al-Qaradawi I Y, Madi N and Al-Thani N J 2006 Appl. Surf. Sci. 2523316

Maadeed M A A, Al-Thani N J and Bader M 2010 Adv. Mater. Res. 83-86 505

Medel F J, Garcia-Alvarez F, Gomez-Barrena E and Puertolas J A 2005 Polym. Degrad. Stabil. 88435

Morlanes M J M, Castell P, Nogués V M, Martinez M T, Alonso P J and Puértolas J A 2011 Compos. Sci. Technol. 71282 
Oral E, Greenbaum E S, Malhi A S, Harris W H and Muratoglu O K 2005 Biomaterials 266657

Perepechko II 1981 An introduction to polymer physics (Moscow: Mir Publishers)

Premnath V, Bellare A, Merrill E W, Jasty M and Harris W H 1999 Polymer 402215

Pritchett J W 2011 J. Long-Term. Eff. Med. 2155

Reis J, Kanagaraj S, Fonseca A, Mathew M T, Silva F C, Potes J, Oliveira M S A and Simoes J A O 2010 Braz. J. Med. Biol. Res. 43476
Sreekanth P S R and Kanagaraj S 2013 J. Mech. Behav. Biomed. Mater. 18140

Stanczyk M and Telega J J 2002 Acta Bioeng. Biomech. 43

Stephens C P, Benson R S, Martinez-Pardo M E, Barker E D, Walker J B and Stephens T P 2005 Nucl. Instr. Meth. Phys. Res. B236 540

Vahid D J, Jagatia M, Jin Z M and Dowson D 2001 J. Biomech. 34 261

Wang H F, Wang J, Deng X Y, Sun H F, Shi Z J and Gu Z N 2004 J. Nanosci. Nanotechnol. 41019 